Published in final edited form as:

Ann Vasc Surg. 2018 February ; 47: 31-42. doi:10.1016/j.avsg.2017.08.021.

\title{
Comparison of Endovascular Stent Grafts for Abdominal Aortic Aneurysm Repair in Medicare Beneficiaries
}

\author{
Dominique B. Buck, MD, PhD¹, Peter A. Soden, MD¹, Sarah E. Deery, MD, MPH ${ }^{1}$, Sara L. \\ Zettervall, MD, MPH ${ }^{1}$, Klaas H.J. Ultee, BSc ${ }^{1}$, Bruce E. Landon ${ }^{2,3}$, A. James O'Malley, PhD, \\ MD, MBA ${ }^{4}$, and Marc L. Schermerhorn, MD ${ }^{1}$ \\ ${ }^{1}$ Department of Vascular and Endovascular Surgery, Beth Israel Deaconess Medical Center, \\ Boston, MA \\ ${ }^{2}$ Department of Medicine, Beth Israel Deaconess Medical Center, Boston, MA \\ ${ }^{3}$ Department of Health Care Policy, Harvard Medical School, Boston, MA \\ ${ }^{4}$ Institute for Health Policy and Clinical Practice, Geisel School of Medicine at Dartmouth, \\ Lebanon, $\mathrm{NH}$
}

\section{Abstract}

Background-Increased renal complications have been suggested with suprarenal stent grafts, but long-term analyses have been limited. Therefore, the purpose of this study was to evaluate the effect of endograft choice on perioperative and long-term outcomes.

\begin{abstract}
Methods-We compared Medicare beneficiaries undergoing endovascular AAA repair from 2005-2008 with endografts with infrarenal fixation and a single docking limb (AneuRx, Excluder) to those with suprarenal fixation and two docking limbs (Zenith), or a unibody configuration (Powerlink). Propensity score weighting accounted for differences in patient characteristics among the different graft formations, and perioperative mortality, complications, and length of stay and four-year rates of survival, rupture, and reintervention were compared.
\end{abstract}

Results-46,171 Medicare beneficiaries were identified including 11,002 (24\%) with suprarenal fixation, 32,909 (71\%) with infrarenal fixation, and 2,260 (5\%) with a unibody graft. After propensity score weighting, there were no significant differences in patients' baseline clinical and demographic characteristics. The suprarenal fixation patients had higher rates of perioperative mortality $(1.7 \%$ vs. $1.3 \%, \mathrm{P}<.01)$, renal failure $(6.0 \%$ vs $4.7 \%, \mathrm{P}<.001)$, and mesenteric ischemia $(0.7$ vs. $0.4 \%, \mathrm{P}<.01)$ and longer length of stay ( 3.4 days vs. 3.0 days, $\mathrm{P}<.001)$ compared to patients with infrarenal fixation. Unibody grafts had higher rates of renal failure (5.9\% vs. $4.7 \%, \mathrm{P}<.001)$, mesenteric ischemia ( $1.0 \%$ vs. $0.4 \%, \mathrm{P}<.001)$, and conversion to open repair $(0.7 \%$ vs. $0.1 \%, \mathrm{P}<.001)$ compared to those with infrarenal fixation and single docking limbs. At four years, mortality remained slightly higher with suprarenal compared to infrarenal

Corresponding Author/Reprints: Marc L. Schermerhorn, 110 Francis St. Suite 5B, Boston, MA 02215; Phone: 617-632-9971; mscherm@bidmc.harvard.edu.

Publisher's Disclaimer: This is a PDF file of an unedited manuscript that has been accepted for publication. As a service to our customers we are providing this early version of the manuscript. The manuscript will undergo copyediting, typesetting, and review of the resulting proof before it is published in its final citable form. Please note that during the production process errors may be discovered which could affect the content, and all legal disclaimers that apply to the journal pertain. 
fixation (30\% vs. $29 \%, \mathrm{P}=.047)$, although these patients had fewer conversions to open repair $(0.6 \%$ vs. $0.9 \%, \mathrm{P}=.03)$ and aneurysm-related reinterventions $(10 \%$ vs. $12 \%, \mathrm{P}<.01)$. At four years, unibody grafts had more aneurysm-related interventions compared to infrarenal fixation grafts $(15 \%$ vs. $12 \%, \mathrm{P}<.01)$ but fewer conversions to open repair $(0.4 \%$ vs. $0.9 \%, \mathrm{P}=.02)$. Late rupture did not differ among the groups.

Conclusions-Compared to infrarenal fixation devices, patients who underwent EVAR with suprarenal fixation had higher perioperative mortality and renal complications but fewer reinterventions including conversion, while the unibody graft had more perioperative complications and aneurysm-related reinterventions, but fewer conversions to open repair. While these differences could be explained by selection bias, these data suggest that further comparative effectiveness analyses should be performed to understand the outcomes following EVAR with suprarenal fixation and unibody grafts.

\section{Keywords}

EVAR; fixation; renal complications; Medicare

\section{Introduction}

Endovascular aneurysm repair (EVAR) has become the primary treatment modality for patients undergoing elective repair of abdominal aortic aneurysms (AAA). ${ }^{1,2}$ Previous research has demonstrated the safety and efficacy of commercially available EVAR stent grafts. ${ }^{2-6}$ Postmarket surveillance, however, has highlighted issues with each of these grafts leading to changes in their design. There are little data, however, comparing the effectiveness of the various stent grafts to help guide a physician's choice of one stent graft over another. While some small, single-institution series have suggested increased rates of renal complications with suprarenal fixation, ${ }^{7,8}$ the majority of studies, including a recent meta-analysis, have shown no differences. ${ }^{9-17}$ These studies, however, are limited by being underpowered. We recently reported that suprarenal fixation was associated with higher rates of perioperative renal complications in a large national sample using the National Surgical Quality Improvement Program. ${ }^{18}$ However, few data exist regarding late outcomes by endograft type. In this study, we aimed to evaluate differences in perioperative and four-year outcomes among commonly used stent grafts amongst Medicare beneficiaries.

\section{Methods}

\section{Patients}

All Medicare beneficiaries who underwent endovascular repair of an intact abdominal aortic aneurysm between 2005 and 2008 were identified and followed until death or censoring at the end of 2009. Only patients continuously enrolled in Medicare parts A and B for at least two years prior to their repair were included. Patients with ruptured abdominal aortic aneurysms, thoracic aneurysms, thoracoabdominal aortic aneurysms, and aortic dissections were excluded. ${ }^{19}$ Beneficiaries who enrolled in health maintenance organizations at any time during the follow-up period were censored from the analyses of late non-fatal complications and reinterventions due to the lack of subsequent claims data. Survival data were available 
for all patients. This study was approved by the institutional review board at Harvard Medical School and informed consent was waived.

\section{Stent Grafts}

Stent graft type was determined from Current Procedural Terminology (CPT) codes. During the study period, there were only specific devices used under each code. The CPT code 34804 represents bifurcated grafts with two docking limbs which was only performed with the Zenith device, which has suprarenal fixation (Table I). The CPT code 34802, representing a bifurcated graft with a single docking limb, was performed using only AneuRx and Excluder, which are both infrarenal devices; notably, we are unable to distinguish between the use of these two devices. Finally, the CPT code 34804 for the unibody bifurcated device represents the use of the Powerlink device, which can be used with suprarenal or infrarenal fixation. Therefore, these patients were not included in the primary analysis of suprarenal vs. infrarenal fixation, but were included in a separate analysis.

\section{Outcomes}

Perioperative surgical complications (e.g. conversion from endovascular to open repair, return to the operating room, etc.) and medical complications (e.g. myocardial infarction, pneumonia) were identified using ICD-9-CM diagnosis and complication codes, as well as physicians' CPT codes identified using both hospital and physician claims. ${ }^{19}$ Discharge disposition (home or facility) and length of stay for each patient was recorded. Mortality was identified from the Medicare Beneficiary Summary File. Perioperative mortality was defined as 30-day and/or in-hospital mortality, and long-term mortality included all deaths during the available follow-up period.

Subsequent AAA-related hospitalizations and reinterventions, including hospitalizations for rupture, major reinterventions (e.g. open repair of the aneurysm/pseudoaneurysm, repair of a graft-enteric fistula or graft infection), and minor reinterventions (e.g., stent-graft extension, coil embolization, aortic or iliac angioplasty, graft thrombectomy) were also identified from both hospital and physician claims.

\section{Statistical Analyses}

The characteristics of the unmatched cohorts were compared using chi-square tests and Student's T-tests for categorical and continuous variables, respectively, or F-tests for simultaneous comparisons across all treatment groups. To account for differences among the groups of patients treated with each type of graft, we used propensity score weighting methods. ${ }^{20-22}$ Using a generalized logistic regression model, we first computed the estimated probability a patient with given characteristics received each stent relative to the other stents on the market at that time. The fitted generalized logistic regression model estimated three probabilities that are constrained to sum to one, corresponding to receiving a suprarenal fixation device (Zenith), an infrarenal fixation device (AneuRx/Excluder), or the unibody (Powerlink) device. The propensity to receive a given stent was equalized or balanced across the treatment groups based on the actual stent received by each patient by weighting observations by the inverse of the estimated probability a patient with the same 
characteristics would receive that stent. With three or more treatment groups, inverse probability weighting has the advantage, compared to pairwise propensity score matching, of ensuring that comparisons between each pair of stents pertain to the same population. We scaled the weights so that the estimated effects of each stent correspond to the average treatment effect (ATE) over all the patients in the sample. Balancing the distribution of propensity scores in the treatment group served as a conduit to balancing the distribution of the predictors in the propensity score model, although this is not guaranteed.

To check for residual imbalances in the distribution of the predictors across the samples of patients receiving each stent, we evaluated the magnitude of the standardized mean differences in the propensity scores across the treatment groups. ${ }^{23}$ We checked whether the distributions of the covariates in the weighted sample were balanced among the groups receiving each stent by evaluating weighted chi-square and t-tests. For the purpose of the manuscript, we discuss the results using the infrarenal fixation devices as the point of reference for comparisons. Tests that compared all three groups simultaneously by using chisquare tests involving higher degrees-of-freedom and F-tests for continuous predictors were also conducted as appropriate.

We estimated the association between the initial treatment strategy and the rate of inhospital death, reintervention, perioperative complications, and long-term complications by computing weighted event rates or hazard-ratios. We evaluated the statistical significance of the differences by using methods that treat the propensity score weights as analytic weights as opposed to frequency weights (analogous to survey analysis). ${ }^{24}$ Each of the outcomes was treated as an event. For perioperative outcomes, tests of proportions were conducted to test for significant differences between each stent and the control stent. We stratified mortality by year and found no indication of changing trend over time and so this was not included in our modeling. In sensitivity analyses, we added patient clinical and demographic characteristics as additional predictors to these models and again found no difference.

We used propensity score weighted Cox proportional hazard models to compare the risk of the long term outcome events among the treatment groups. The proportional hazard assumption is reasonable for comparisons between different stents as their risk profiles track closely over time, unlike comparisons of endovascular versus open surgical repair, which have different risk profiles over the perioperative period compared to subsequent follow-up. In analyses of time-to-death, the end of the follow-up period was the only source of censoring. In analyses of nonfatal events, death was a censoring event as was subsequent enrollment in a Medicare Advantage health plan. In a sensitivity analysis we also estimated competing risk models of time to a given non-fatal event or death (i.e., whichever occurred first) to avoid relying on independent censoring due to death for the results to be valid.

The estimated effects obtained from Cox proportional hazard models are log-hazard ratios. To convert these to fixed-time event probabilities, we estimated a logistic regression model in which the unit of analysis was whether an individual experienced the outcome event in a given month. The probability of the outcome event occurring by month $t$ was then computed by evaluating the product of the estimated conditional survival probabilities over the earlier months emulating the product-moment calculations performed when evaluating Kaplan- 
Meier curves. This procedure allowed estimating both the event probability and its associated standard error (thus, also enabling confidence intervals and P-values). The analyses were performed using SAS version 9.3, Copyright, SAS Institute Inc., Cary, NC, USA.

\section{Results}

We studied 46,171 Medicare beneficiaries, of whom 11,002 (24\%) had suprarenal fixation, 32,909 (71\%) had infrarenal fixation, and 2,260 (5\%) received the Powerlink unibody stent graft (Table II). After propensity score weighting, there were no significant differences in patients' baseline demographic and clinical characteristics among the three stent graft groups. The mean age after propensity score weighting was approximately 77 years old with $82 \%$ being male and $95 \%$ white across all three groups. Only $4 \%$ of operations had an urgent admission, $1.4 \%$ had a myocardial infarction in the prior six months, $14 \%$ had congestive heart failure, and less than $1 \%$ had end-stage renal disease across groups, with no significant differences between groups.

\section{Perioperative Outcomes}

Compared to infrarenal fixation, suprarenal fixation was associated with significantly higher perioperative mortality $(1.7 \%$ vs. $1.3 \%, \mathrm{P}<.01)$, acute renal failure $(6.0 \%$ vs. $4.7 \%, \mathrm{P}<$. $001)$, mesenteric ischemia $(0.7 \%$ vs. $0.4 \%, \mathrm{P}<.01)$, embolectomy $(1.1 \%$ vs. $0.8 \%, \mathrm{P}<.01)$, myocardial infarction $(2.8 \%$ vs. $2.2 \%, \mathrm{P}<.001)$, and pneumonia $(4.6 \%$ vs. $3.7 \%, \mathrm{P}<.001)$ (Table III). Additionally, length of stay was longer ( 3.4 days vs. 3.0 days, $\mathrm{P}<.001$ ), and readmission within 30 days was more common $(12 \%$ vs. $10 \%, \mathrm{P}<.001)$. Patients with suprarenal fixation were also less likely to be discharged home ( $94 \%$ vs. $95 \%, \mathrm{P}<.001)$.

Compared to patients with an infrarenal fixation, the use of the Powerlink unibody stent grafts had an increase in observed mortality that was not statistically significant $(1.7 \%$ vs. $1.3 \%, \mathrm{P}=.19$ ) with a similar effect size to that of two docking limb stent grafts (Relative Risk 1.3, 95\% CI: 1.1-1.6 and 1.3, 0.9-1.8 for suprarenal fixation and Powerlink, respectively). Patients treated with Powerlink had higher rates of conversions to open repair ( $0.7 \%$ vs. $0.1 \%, \mathrm{P}<.001)$, acute renal failure $(5.9 \%$ vs. $4.7 \%, \mathrm{P}=.02)$, mesenteric ischemia ( $1.0 \%$ vs. $0.4 \%, \mathrm{P}<.001)$, and embolectomy ( $1.4 \%$ vs. $0.8 \%, \mathrm{P}=.01)$ compared to those with infrarenal fixation devices. Additionally, length of stay was slightly longer in the Powerlink group ( 3.3 days vs. 3.0 days, $\mathrm{P}=.02$ ).

\section{Four-Year Outcomes}

Mortality after four years of follow-up remained significantly higher in patients with suprarenal compared to infrarenal fixation ( $30 \%$ vs. $29 \%, \mathrm{P}=.047)$ (Table IVa). In contrast, AAA-related reinterventions ( $10 \%$ vs. $12 \%, \mathrm{P}<.01)$ and conversion to open repair $(0.6 \%$ vs. $0.9 \%, \mathrm{P}=.03$ ) were less common in patients with suprarenal fixation. The difference in reinterventions was primarily driven by lower rates of placement of extension cuffs during follow-up $(2.9 \%$ vs. $4.1 \%, \mathrm{P}<.001)$ in the suprarenal fixation patients.

At four-year follow-up, patients with Powerlink endografts had more AAA-related interventions $(15 \%$ vs. $12 \%, \mathrm{P}<.01)$ compared to infrarenal fixation. This was primarily 
due to the higher rates of placement of extension cuffs with Powerlink (7.8\% vs. $4.1 \%, \mathrm{P}<$. 001).

However, Powerlink was associated with fewer conversions to open repair ( $0.4 \%$ vs. $0.8 \%, \mathrm{P}$ $=.02$ ) (Table IVb). Rupture and major reinterventions did not differ at four-year follow-up between the Powerlink device and those with infrarenal fixation.

\section{Discussion}

In this large, nationally representative study, we found that suprarenal fixation devices were associated with higher perioperative mortality and morbidity rates and longer length of stay compared to the infrarenal fixation devices, but were associated with lower rates of minor aneurysm-related reinterventions (primarily extension cuffs) and conversion to open repair during follow-up. Compared to the infrarenal fixation devices, Powerlink had a nonsignificantly higher perioperative and late mortality, and a significantly higher rate of perioperative complications. Also, during follow-up, there were more reinterventions in the Powerlink group, but fewer cases of conversion to open repair, although the rate of conversion to open repair overall was very low at $<1 \%$.

Studies of the comparative effectiveness of technologies such as stent grafts are challenging because these products tend to evolve over time, so the results of long-term analyses are often moot by the time of their publication. Consequently, each stent graft studied in this analysis has undergone revisions based on deficiencies identified in post-marketing surveillance and some are no longer in use. By analyzing years 2005 to 2008, however, we were able to capture the second and third generations of these stent grafts, which are more similar to versions that are available today, although some changes to these endografts have occurred since our study period. In addition, we find small but statistically significant differences in perioperative and longer term outcomes that suggest the need for continued monitoring.

For example, the AneuRx by Medtronic, which is no longer available, was a Dacron single docking limb stent graft without fixation appendices, although there was no suprarenal component so it was included in the infrarenal fixation group for the purposes of these analyses. Concerns regarding significant device migration with the AneuRx system ${ }^{25-28}$ led to a notification issued by the FDA in $2003 .{ }^{29}$ To address this concern for migration, attributed to the device's approval for use in shorter necks, the manufacturer recommended limiting its use to AAAs with a $15 \mathrm{~mm}$ neck length that same year. However, our study suggests that these recommendations did not eliminate this concern. We found a higher rate of extension cuffs and conversion to open repair, which may be due to stent graft migration, for the infrarenal fixation group, which included Aneurx and Excluder, although we could not distinguish between the two.

The original Excluder by Gore, introduced in 2002, was a lower profile PTFE and nitinol stentgraft with infrarenal fixation hooks to prevent migration. Early problems with postoperative sac expansion ${ }^{30-34}$ despite an absence of radiographic endoleak were related to material permeability ${ }^{33}, 35-38$, and led to a low-permeability Excluder, introduced in 
2004. ${ }^{34,35,39-42}$ The device's low profile allowed for an increase in the treatment of women and those with ilio-femoral occlusive disease.

Approved in 2003, the Zenith by Cook is a bifurcated graft with two docking limbs and a low-permeability Dacron design with suprarenal bare stent and hooks to improve fixation and minimize migration. It has been associated with high rates of sac regression ${ }^{43}, 44$ but was found to have limbs prone to kinking in tortuous and narrow iliac arteries, thought to be due to its interrupted design. ${ }^{43,45-47}$ To avoid the risk of limb occlusion from kinking, selfexpandable stents inside the Zenith stent graft were occasionally added and further graft limb modifications were introduced after our study period. ${ }^{47-49}$ In 2006, Cook introduced a large-neck version of the Zenith stent graft, to allow for treatment of patients with larger aortic neck diameters than was previously possible with existing stent grafts at the time. Furthermore, Zenith was the first graft with suprarenal stenting to prevent migration. However, the caveat to this is that it may have been chosen for those patients with suboptimal neck anatomy, which would increase the technical difficulty of the procedure and potentially lead to more perioperative complications, as a result of the challenging anatomy rather than from the graft itself. Additionally, patients with larger neck diameters may represent a subgroup of patients destined to have higher complication rates. Finally, the Zenith two docking limb stent graft, with a 21 French outer diameter, had a larger profile and was stiffer than the other stent grafts, which could make implantation more difficult and therefore may be associated with higher rates of perioperative complications, as we observed in our study. The Zenith Flex graft was introduced in 2007 with a hydrophilic coating and increased flexibility to minimize trauma during insertion.

The Powerlink by Endologix, which was FDA approved in 2004, is a unibody bifurcated expandable PTFE stent graft with a metallic endoskeleton, that can have either suprarenal or infrarenal fixation. ${ }^{50,51}$ It was noted to have access problems in the delivery system ${ }^{52,53}$ that were addressed after our study period. ${ }^{51}$ The Powerlink's graft bifurcation sits on the aortic bifurcation to minimize migration; however, an extension cuff to obtain proximal seal is almost uniformly required, which may negate this potential benefit, but our current data did not allow us to evaluate this fully.

It is hypothesized that the longer main body and external billowing fabric of the unibody stent graft (Powerlink) may decrease type 2 endoleaks, however we did not find lower rates of reintervention, including embolization, in the Powerlink group, although conversion to open repair was significantly lower compared to the infrarenal fixation group. While the higher rate of conversion to open repair with infrarenal compared to suprarenal fixation endografts can be postulated to be related to graft migration and the need for extension cuffs, this does not appear to be the case for the comparison to unibody as the unibody had a higher rate of cuff placement than single-limb endografts. The failure mode leading to cuff placement with the Powerlink may be from component separation that may be more likely to be treatable with cuff placement rather than conversion to open repair. ${ }^{54}$ However, our dataset does not allow us to distinguish where extension cuffs were placed to further speculate on why they were used. 
While this study benefits from the large study size and inclusive population, the incorporation of physician CPT codes, determination of coexisting conditions from prior encounters, and the use of propensity score weighted matching to adjust for all measured comorbidities, there are several limitations. Medicare data lacks any anatomic detail including aneurysm diameter, neck diameter and length, iliac diameter, and tortuosity, which could contribute to device selection. Furthermore, we know that a large proportion of endografts are deployed outside of the manufacturer's instruction for use making us unable to make generalizations based on manufacturer guidelines for each endograft type. ${ }^{55}$ Also, because we examined multiple outcomes, our analyses were subject to spurious correlations due to multiple comparisons. In addition, inverse probability weighting may over-represent certain types of patients in our cohort, however we performed sensitivity analyses to adjust for residual differences as stated in our methods. Despite this, we are unable to comment on the mechanism of the differences noted without more granular anatomic data; therefore, we hope that this study provides an impetus for further evaluation of endograft complications by device type. Finally, we realize that endograft technology continues to evolve and our results may be outdated; however, we believe this critical ongoing analysis of technology is necessary and important. Such a limitation will always be part of a retrospective real-world analysis of rapidly changing technology but reliance on device trials for all data on complications related to these products is not sufficient. We hope that these data encourage vascular surgery registries to add important anatomic variables to their data collection instruments to enhance future comparative analysis studies of endografts.

\section{Conclusion}

Despite our inability to distinguish specific endografts in the infrarenal fixation group and potential selection bias hampering our early outcome comparison, the suprarenal fixation stent grafts were associated with fewer reinterventions, but higher perioperative mortality and morbidity, compared to infrarenal fixation devices. The unibody Powerlink had more perioperative complications and aneurysm-related reinterventions, but fewer conversions to open repair compared to infrarenal fixation devices. Future comparative analyses of the different and evolving stent grafts with the inclusion of anatomic detail will be important to guide device selection for individual patients and to guide future technologic improvements.

\section{Acknowledgments}

PS, SD, and SZ were supported by the NIH T32 HarvardLongwood Research Training in Vascular Surgery Grant 5T32HL007734-22

\section{References}

1. Drury D, Michaels JA, Jones L, Ayiku L. Systematic review of recent evidence for the safety and efficacy of elective endovascular repair in the management of infrarenal abdominal aortic aneurysm. The British journal of surgery. 2005; 92(8):937-46. [PubMed: 16034817]

2. Schermerhorn ML, O’Malley AJ, Jhaveri A, Cotterill P, Pomposelli F, Landon BE. Endovascular vs. open repair of abdominal aortic aneurysms in the Medicare population. N Engl J Med. 2008; 358(5):464-74. [PubMed: 18234751] 
3. White GH, May J, McGahan T, Yu W, Waugh RC, Stephen MS, et al. Historic control comparison of outcome for matched groups of patients undergoing endoluminal versus open repair of abdominal aortic aneurysms. J Vasc Surg. 1996; 23(2):201-11. discussion 11-2. [PubMed: 8637097]

4. Zarins CK, White RA, Schwarten D, Kinney E, Diethrich EB, Hodgson KJ, et al. AneuRx stent graft versus open surgical repair of abdominal aortic aneurysms: multicenter prospective clinical trial. J Vasc Surg. 1999; 29(2):292-305. discussion 6-8. [PubMed: 9950987]

5. De Bruin JL, Baas AF, Buth J, Prinssen M, Verhoeven EL, Cuypers PW, et al. Long-term outcome of open or endovascular repair of abdominal aortic aneurysm. N Engl J Med. 2010; 362(20):1881-9. [PubMed: 20484396]

6. Lederle FA, Freischlag JA, Kyriakides TC, Matsumura JS, Padberg FT Jr, Kohler TR, et al. Longterm comparison of endovascular and open repair of abdominal aortic aneurysm. N Engl J Med. 2012; 367(21):1988-97. [PubMed: 23171095]

7. Bockler D, Krauss M, Mansmann U, Halawa M, Lange R, Probst T, et al. Incidence of renal infarctions after endovascular AAA repair: relationship to infrarenal versus suprarenal fixation. J Endovasc Ther. 2003; 10(6):1054-60. [PubMed: 14723570]

8. Saratzis A, Sarafidis P, Melas N, Khaira H. Comparison of the impact of open and endovascular abdominal aortic aneurysm repair on renal function. J Vasc Surg. 2014; 60(3):597-603. [PubMed: 24794276]

9. Alsac JM, Zarins CK, Heikkinen MA, Karwowski J, Arko FR, Desgranges P, et al. The impact of aortic endografts on renal function. J Vasc Surg. 2005; 41(6):926-30. [PubMed: 15944586]

10. Broker HS, Foteh KI, Murphy EH, Davis CM, Clagett GP, Modrall JG, et al. Device-specific aneurysm sac morphology after endovascular aneurysm repair: evaluation of contemporary graft materials. J Vasc Surg. 2008; 47(4):702-6. discussion 7. [PubMed: 18296015]

11. Lau LL, Hakaim AG, Oldenburg WA, Neuhauser B, McKinney JM, Paz-Fumagalli R, et al. Effect of suprarenal versus infrarenal aortic endograft fixation on renal function and renal artery patency: a comparative study with intermediate follow-up. J Vasc Surg. 2003; 37(6):1162-8. [PubMed: 12764259]

12. Miller LE, Razavi MK, Lal BK. Suprarenal versus infrarenal stent graft fixation on renal complications after endovascular aneurysm repair. J Vasc Surg. 2015; 61(5):1340-9 e1. [PubMed: 25736780]

13. Ouriel K, Clair DG, Greenberg RK, Lyden SP, O’Hara PJ, Sarac TP, et al. Endovascular repair of abdominal aortic aneurysms: device-specific outcome. J Vasc Surg. 2003; 37(5):991-8. [PubMed: 12756344]

14. Parmer SS, Carpenter JP, Endologix I. Endovascular aneurysm repair with suprarenal vs infrarenal fixation: a study of renal effects. J Vasc Surg. 2006; 43(1):19-25. [PubMed: 16414382]

15. Pisimisis GT, Bechara CF, Barshes NR, Lin PH, Lai WS, Kougias P. Risk factors and impact of proximal fixation on acute and chronic renal dysfunction after endovascular aortic aneurysm repair using glomerular filtration rate criteria. Ann Vasc Surg. 2013; 27(1):16-22. [PubMed: 23088805]

16. Sheehan MK, Ouriel K, Greenberg R, McCann R, Murphy M, Fillinger M, et al. Are type II endoleaks after endovascular aneurysm repair endograft dependent? J Vasc Surg. 2006; 43(4):65761. [PubMed: 16616216]

17. Tonnessen BH, Sternbergh WC 3rd, Money SR. Mid- and long-term device migration after endovascular abdominal aortic aneurysm repair: a comparison of AneuRx and Zenith endografts. J Vasc Surg. 2005; 42(3):392-400. discussion-1. [PubMed: 16171578]

18. Zettervall SL, Soden PA, Deery SE, Ultee K, Shean KE, Shuja F, et al. Comparison of Renal Complications between Endografts with Suprarenal and Infrarenal Fixation. Eur J Vasc Endovasc Surg. 2017

19. Schermerhorn ML, Buck DB, O’Malley AJ, Curran T, McCallum JC, Darling J, et al. Long-Term Outcomes of Abdominal Aortic Aneurysm in the Medicare Population. N Engl J Med. 2015; 373(4):328-38. [PubMed: 26200979]

20. Stuart EA, Huskamp HA, Duckworth K, Simmons J, Song Z, Chernew M, et al. Using propensity scores in difference-in-differences models to estimate the effects of a policy change. Health Serv Outcomes Res Methodol. 2014; 14(4):166-82. [PubMed: 25530705] 
21. McCaffrey DF, Griffin BA, Almirall D, Slaughter ME, Ramchand R, Burgette LF. A tutorial on propensity score estimation for multiple treatments using generalized boosted models. Stat Med. 2013; 32(19):3388-414. [PubMed: 23508673]

22. Griffin BA, Ramchand R, Almirall D, Slaughter ME, Burgette LF, McCaffery DF. Estimating the causal effects of cumulative treatment episodes for adolescents using marginal structural models and inverse probability of treatment weighting. Drug Alcohol Depend. 2014; 136:69-78.

[PubMed: 24440050]

23. Gu XSRP. Comparison of multivariate matching methods: structures, distances, and algorithms. J Comput Graph Statist. 1993; 2(4):405-20.

24. Moen EL, Fricano-Kugler CJ, Luikart BW, O’Malley AJ. Analyzing Clustered Data: Why and How to Account for Multiple Observations Nested within a Study Participant? PLoS One. 2016; 11(1):e0146721. [PubMed: 26766425]

25. Conners MS 3rd, Sternbergh WC, 3rd, Carter G, Tonnessen BH, Yoselevitz M, Money SR. Endograft migration one to four years after endovascular abdominal aortic aneurysm repair with the AneuRx device: a cautionary note. J Vasc Surg. 2002; 36(3):476-84. [PubMed: 12218970]

26. Sampaio SM, Panneton JM, Mozes G, Andrews JC, Noel AA, Kalra M, et al. AneuRx device migration: incidence, risk factors, and consequences. Annals of vascular surgery. 2005; 19(2):17885. [PubMed: 15782271]

27. Cao P, Verzini F, Zannetti S, De Rango P, Parlani G, Lupattelli L, et al. Device migration after endoluminal abdominal aortic aneurysm repair: analysis of 113 cases with a minimum follow-up period of 2 years. J Vasc Surg. 2002; 35(2):229-35. [PubMed: 11854719]

28. Zarins CK, Bloch DA, Crabtree T, Matsumoto AH, White RA, Fogarty TJ. Stent graft migration after endovascular aneurysm repair: importance of proximal fixation. J Vasc Surg. 2003; 38(6): 1264-72. discussion 72. [PubMed: 14681625]

29. Feigal, D, Jr. FDA Public Health Notification: Updated Data on Mortality Associated with Medtronic AVE AneuRx ${ }^{\circledR}$ Stent Graft System. Dec. 2003 http://www.fda.gov/MedicalDevices/ Safety/AlertsandNotices/PublicHealthNotifications/ucm062158.htm]

30. Bertges DJ, Chow K, Wyers MC, Landsittel D, Frydrych AV, Stavropoulos W, et al. Abdominal aortic aneurysm size regression after endovascular repair is endograft dependent. J Vasc Surg. 2003; 37(4):716-23. [PubMed: 12663968]

31. Cho JS, Dillavou ED, Rhee RY, Makaroun MS. Late abdominal aortic aneurysm enlargement after endovascular repair with the Excluder device. J Vasc Surg. 2004; 39(6):1236-41. discussion 21412. [PubMed: 15192562]

32. van der Laan MJ, Prinssen M, Bertges D, Makaroun MS, Blankensteijn JD. Does the type of endograft affect AAA volume change after endovascular aneurysm repair? J Endovasc Ther. 2003; 10(3):406-10. [PubMed: 12932148]

33. Fillinger M, Excluder Bifurcated Endoprosthesis Clinical I. Three-dimensional analysis of enlarging aneurysms after endovascular abdominal aortic aneurysm repair in the Gore Excluder Pivotal clinical trial. J Vasc Surg. 2006; 43(5):888-95. [PubMed: 16678678]

34. Tanski W 3rd, Fillinger M. Outcomes of original and low-permeability Gore Excluder endoprosthesis for endovascular abdominal aortic aneurysm repair. J Vasc Surg. 2007; 45(2):2439. [PubMed: 17263996]

35. Kong LS, MacMillan D, Kasirajan K, Milner R, Dodson TF, Salam AA, et al. Secondary conversion of the Gore Excluder to operative abdominal aortic aneurysm repair. J Vasc Surg. 2005; 42(4):631-8. [PubMed: 16242545]

36. Matsumura JS, Brewster DC, Makaroun MS, Naftel DC. A multicenter controlled clinical trial of open versus endovascular treatment of abdominal aortic aneurysm. J Vasc Surg. 2003; 37(2):26271. [PubMed: 12563194]

37. Mennander A, Pimenoff G, Heikkinen M, Partio T, Zeitlin R, Salenius JP. Nonoperative approach to endotension. J Vasc Surg. 2005; 42(2):194-9. [PubMed: 16102612]

38. Risberg B, Delle M, Eriksson E, Klingenstierna H, Lonn L. Aneurysm sac hygroma: a cause of endotension. J Endovasc Ther. 2001; 8(5):447-53. [PubMed: 11718401] 
39. Bush RL, Najibi S, Lin PH, Weiss VJ, MacDonald MJ, Redd DC, et al. Early experience with the bifurcated Excluder endoprosthesis for treatment of the abdominal aortic aneurysm. J Vasc Surg. 2001; 34(3):497-502. [PubMed: 11533603]

40. Bastos Goncalves F, Jairam A, Voute MT, Moelker AD, Rouwet EV, ten Raa S, et al. Clinical outcome and morphologic analysis after endovascular aneurysm repair using the Excluder endograft. J Vasc Surg. 2012; 56(4):920-8. [PubMed: 22703975]

41. Curci JA, Fillinger MF, Naslund TC, Rubin BG, Excluder Bifurcated Endoprosthesis I. Clinical trial results of a modified gore excluder endograft: comparison with open repair and original device design. Ann Vasc Surg. 2007; 21(3):328-38. [PubMed: 17484969]

42. Kibbe MR, Matsumura JS, Excluder I. The Gore Excluder US multi-center trial: analysis of adverse events at 2 years. Seminars in vascular surgery. 2003; 16(2):144-50. [PubMed: 12920685]

43. Greenberg RK, Chuter TA, Sternbergh WC 3rd, Fearnot NE, Zenith I. Zenith AAA endovascular graft: intermediate-term results of the US multicenter trial. J Vasc Surg. 2004; 39(6):1209-18. [PubMed: 15192559]

44. Sternbergh WC 3rd, Money SR, Greenberg RK, Chuter TA, Zenith I. Influence of endograft oversizing on device migration, endoleak, aneurysm shrinkage, and aortic neck dilation: results from the Zenith Multicenter Trial. J Vasc Surg. 2004; 39(1):20-6. [PubMed: 14718806]

45. Alric P, Hinchliffe RJ, MacSweeney ST, Wenham PW, Whitaker SC, Hopkinson BR. The Zenith aortic stent-graft: a 5-year single-center experience. J Endovasc Ther. 2002; 9(6):719-28. [PubMed: 12546570]

46. Baum RA, Shetty SK, Carpenter JP, Soulen MC, Velazquez OC, Shlansky-Goldberg RD, et al. Limb kinking in supported and unsupported abdominal aortic stent-grafts. Journal of vascular and interventional radiology : JVIR. 2000; 11(9):1165-71. [PubMed: 11041473]

47. Sivamurthy N, Schneider DB, Reilly LM, Rapp JH, Skovobogatyy H, Chuter TA. Adjunctive primary stenting of Zenith endograft limbs during endovascular abdominal aortic aneurysm repair: implications for limb patency. J Vasc Surg. 2006; 43(4):662-70. [PubMed: 16616217]

48. Bos WT, Tielliu IF, Zeebregts CJ, Prins TR, van den Dungen JJ, Verhoeven EL. Results of endovascular abdominal aortic aneurysm repair with the Zenith stent-graft. European journal of vascular and endovascular surgery : the official journal of the European Society for Vascular Surgery. 2008; 36(6):653-60.

49. Oshin OA, Fisher RK, Williams LA, Brennan JA, Gilling-Smith GL, Vallabhaneni SR, et al. Adjunctive iliac stents reduce the risk of stent-graft limb occlusion following endovascular aneurysm repair with the Zenith stent-graft. J Endovasc Ther. 2010; 17(1):108-14. [PubMed: 20199276]

50. Carpenter JP, Endologix I. Midterm results of the multicenter trial of the powerlink bifurcated system for endovascular aortic aneurysm repair. J Vasc Surg. 2004; 40(5):849-59. [PubMed: 15557896]

51. Wang GJ, Carpenter JP, Endologix I. The Powerlink system for endovascular abdominal aortic aneurysm repair: six-year results. J Vasc Surg. 2008; 48(3):535-45. [PubMed: 18635335]

52. Nano G, Dalainas I, Volpe P, Casana R, Lupattelli T, Paroni G, et al. A variant deployment technique for the powerlink bifurcated endograft. J Endovasc Ther. 2005; 12(6):638-41. [PubMed: 16363891]

53. Qu L, Raithel D. Experience with the Endologix Powerlink endograft in endovascular repair of abdominal aortic aneurysms with short and angulated necks. Perspectives in vascular surgery and endovascular therapy. 2008; 20(2):158-66. [PubMed: 18573806]

54. Skibba AA, Evans JR, Greenfield DT, Yoon HR, Katras T, Ouriel K, et al. Management of late main-body aortic endograft component uncoupling and type IIIa endoleak encountered with the Endologix Powerlink and AFX platforms. J Vasc Surg. 2015; 62(4):868-75. [PubMed: 26141699]

55. Schanzer A, Greenberg RK, Hevelone N, Robinson WP, Eslami MH, Goldberg RJ, et al. Predictors of abdominal aortic aneurysm sac enlargement after endovascular repair. Circulation. 2011; 123(24):2848-55. [PubMed: 21478500] 
Buck et al.

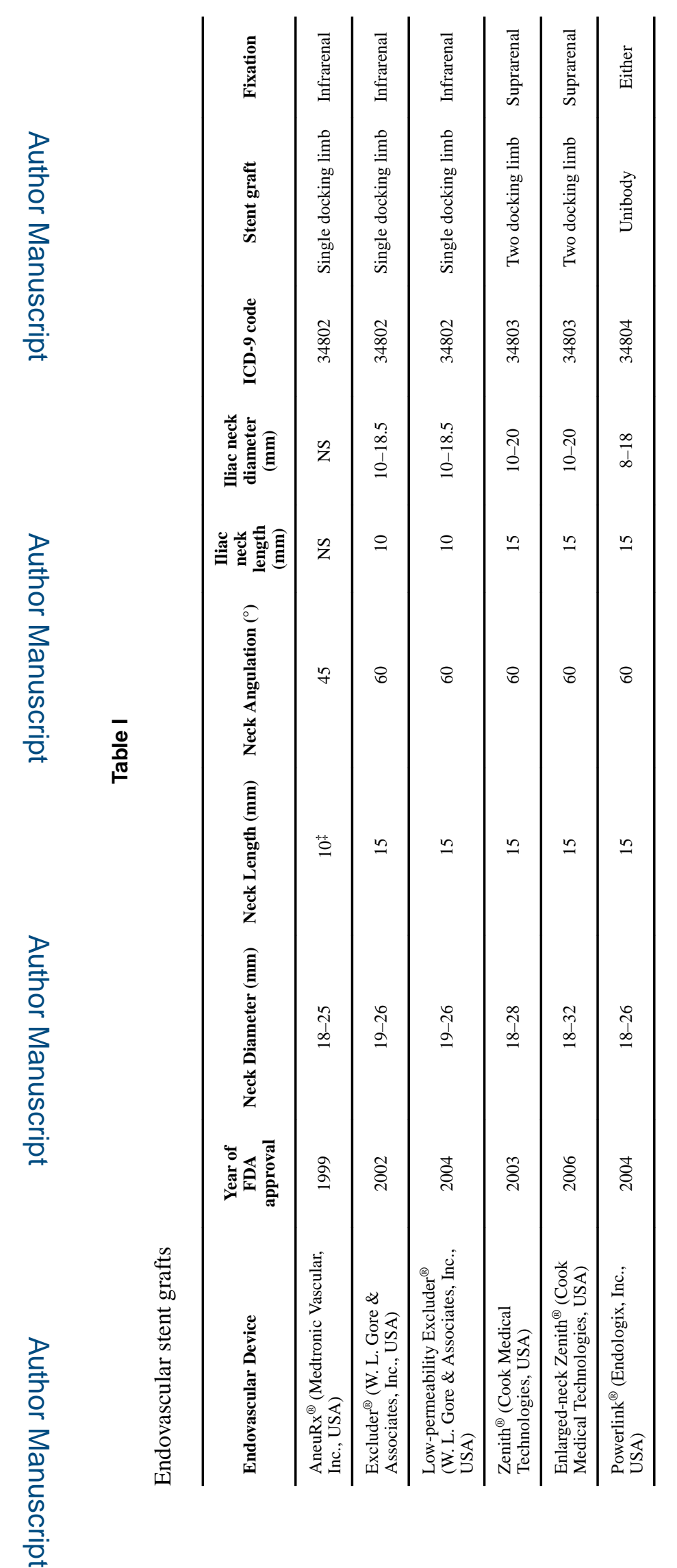

Ann Vasc Surg. Author manuscript; available in PMC 2019 February 01. 


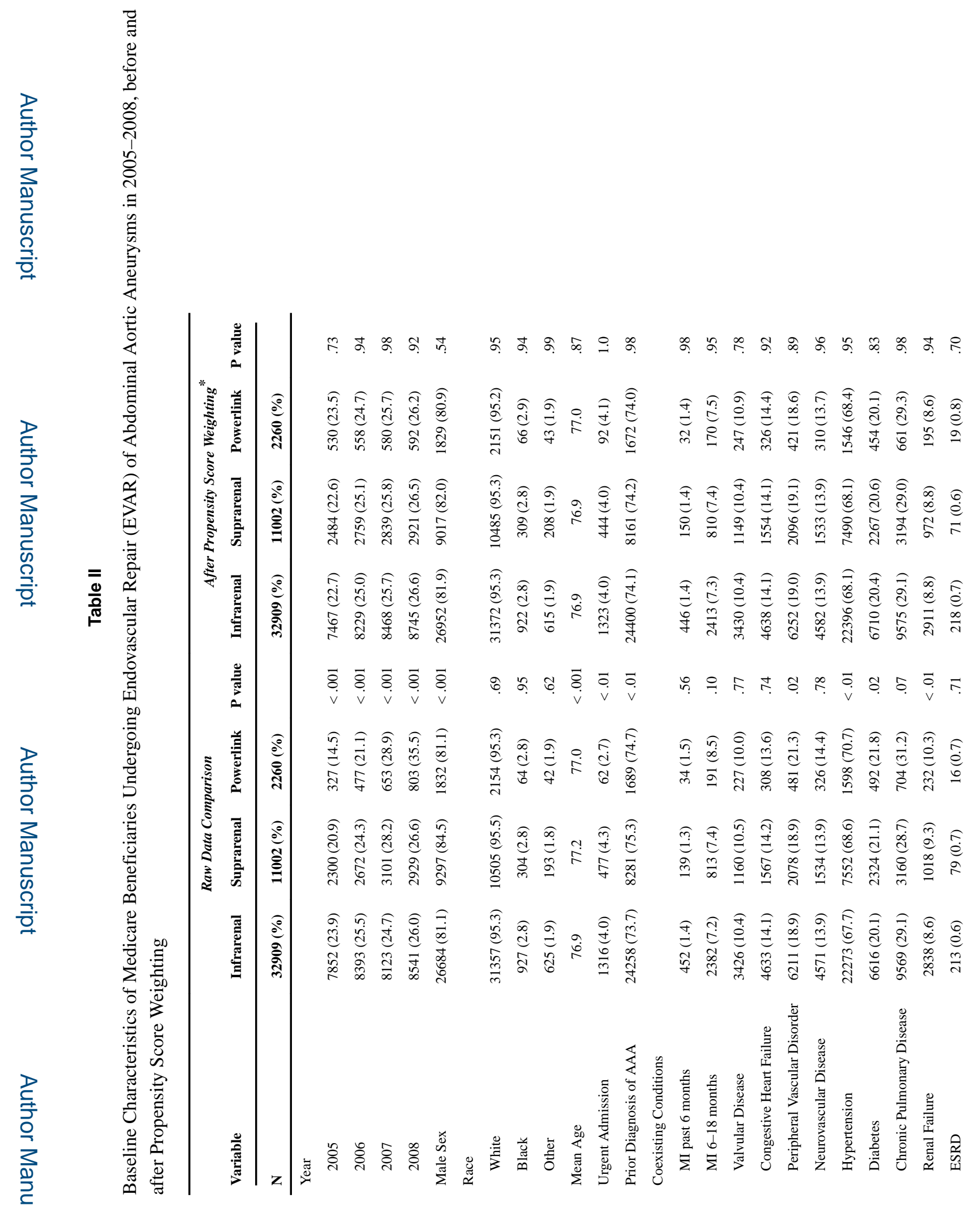


Buck et al.

Page 14

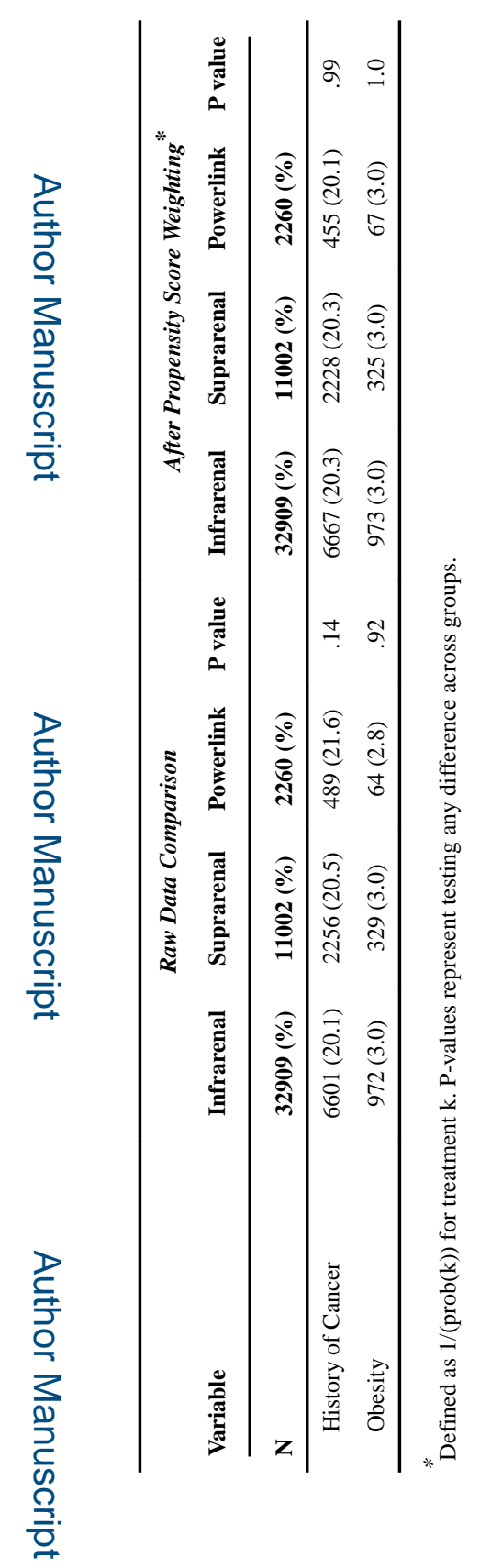

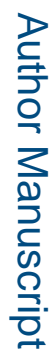

Ann Vasc Surg. Author manuscript; available in PMC 2019 February 01. 




Ann Vasc Surg. Author manuscript; available in PMC 2019 February 01. 


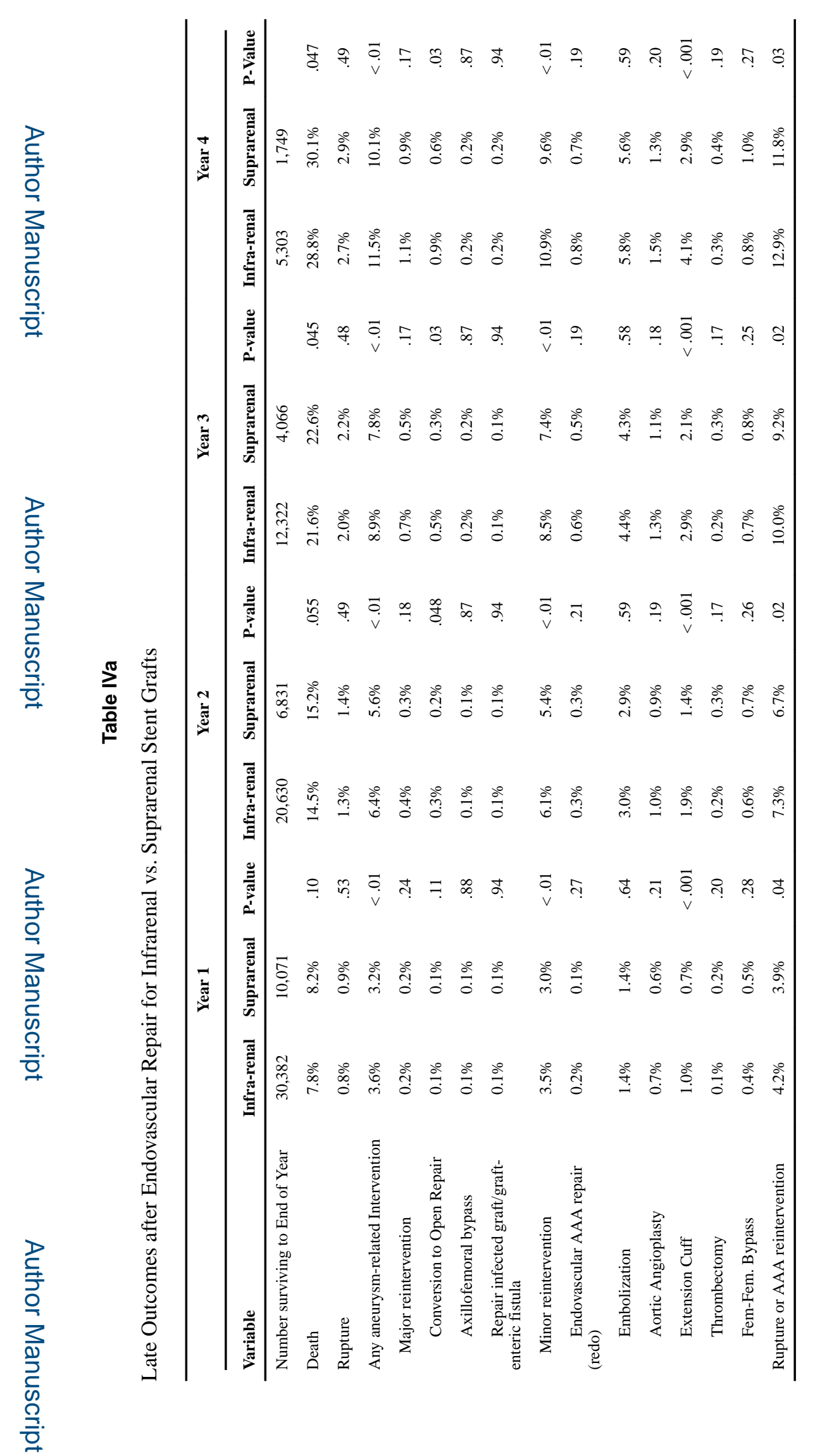

Ann Vasc Surg. Author manuscript; available in PMC 2019 February 01. 


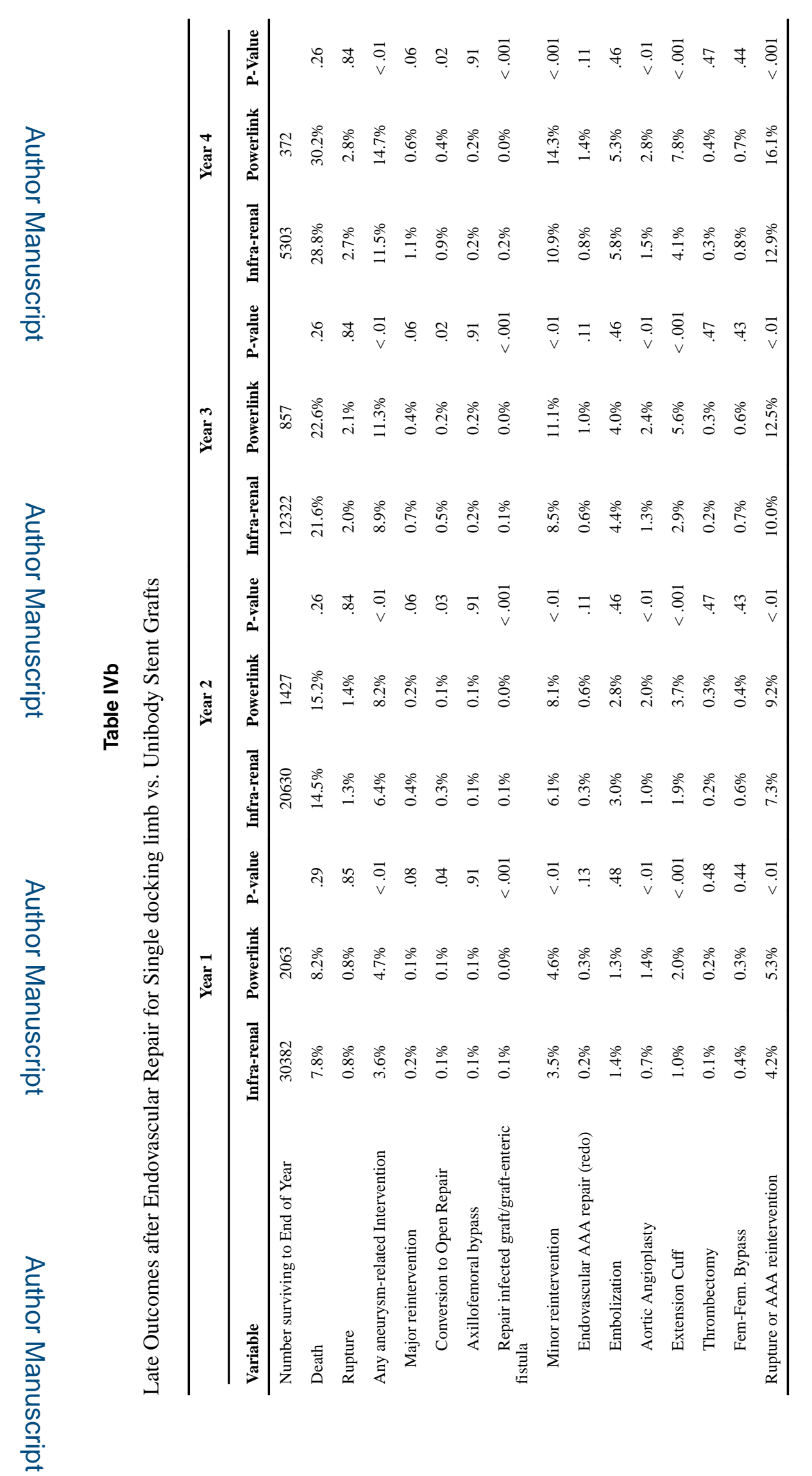

Ann Vasc Surg. Author manuscript; available in PMC 2019 February 01. 